\title{
AIR POLLUTION SIMULATION FROM CIREBON POWER PLANT ACTIVITY
}

\author{
Muhaimin $^{1 *}$, Eko Sugiharto ${ }^{2}$, Adhitasari Suratman ${ }^{2}$ \\ ${ }^{1}$ Program Studi Pendidikan Kimia FMIPA, Universitas Islam indonesia, Yogyakarta \\ ${ }^{2}$ Ilmu Kimia FMIPA, Universitas Gadjah Mada, Yogyakarta \\ *email: el.muhaimin@gmail.com
}

\begin{abstract}
ABTRACT
Air pollution modelling from Cirebon power plant activity has been performed by using gaussian plume model. Gaussian plume equation was applied to predict the distribution and concentration of pollutant gases in the air. The aims of this research were to determine the concentration of pollutants in ambient air as a result of power plant activities and modeling dispersion of pollutants in the air from two stacks. The results showed that the maximum concentration for all parameters still be below the Threshold Limit Value permitted by the government regulation. The maximum concentration of $\mathrm{SO}_{\mathrm{x}}$ is $36.89 \mu \mathrm{g} / \mathrm{m}^{3}$, while $\mathrm{NO}_{\mathrm{x}}$ is $31.25 \mu \mathrm{g} / \mathrm{m}^{3}$. The simulation by using two stacks the maksimum of $\mathrm{SO}_{\mathrm{x}}$ concentration is $52.95 \mu \mathrm{g} / \mathrm{m}^{3}$ and $\mathrm{NO}_{\mathrm{x}}$ with concentration $44.86 \mu \mathrm{g} / \mathrm{m}^{3}$.
\end{abstract}

Key words: concentration, gaussian plume, modelling, power plant,

\section{ABSTRAK}

Telah dilakukan penelitian simulasi sebaran polutan dari aktivitas PLTU Cirebon dengan menggunakan model gaussian plume. Persamaan gaussian plume digunakan untuk memprediksikan persebaran dan konsentrasi gas polutan di udara. Tujuan dari penelitian ini adalah untuk mengetahui konsentrasi polutan di udara ambien akibat dari aktivitas PLTU dan pemodelan dispersi polutan di udara yang berasal dari dua cerobong asap. Hasil penelitian menunjukkan bahwa konsentrasi maksimum untuk semua parameter masih berada di bawah baku mutu yang telah ditetapkan. Adapun konsentrasi maksimum untuk parameter $\mathrm{SO}_{\mathrm{x}}$ sebesar $36,89 \mu \mathrm{g} / \mathrm{m}^{3}$ sedangkan $\mathrm{NO}_{\mathrm{x}}$ adalah $31,25 \mu \mathrm{g} / \mathrm{m}^{3}$. Sedangkan simulasi dengan menggunakan dua cerobong asap konsentrasi maksimum $\mathrm{SO}_{\mathrm{x}}$ sebesar $52,95 \mu \mathrm{g} / \mathrm{m}^{3}$ dan $\mathrm{NO}_{\mathrm{x}}$ sebesar $44,86 \mu \mathrm{g} / \mathrm{m}^{3}$.

Kata kunci: gaussian plume, PLTU, sebaran

\section{Pendahuluan}

Keberadaan pembangkit listrik di sekitar pemukiman penduduk membuat kebutuhan masyarakat sekitar menjadi terpenuhi, akan tetapi dengan adanya emisi gas yang berasal dari pembangkit listrik membuat kebutuhan untuk mendapatkan udara segar kurang terpenuhi dan dapat menimbulkan penyakit bagi masyarakat di lingkungan sekitar pembangkit listrik. Sumber emisi yang berasal dari PLTU, memiliki dampak yang besar dan signifikan pada wilayah pemukiman disekitar PLTU (Bijaksana et al., 2012 dan $\mathrm{Wu}$ et al., 2012). Emisi gas $\mathrm{SO}_{\mathrm{x}}$ dan $\mathrm{NO}_{\mathrm{x}}$ dari pembangkit listrik dengan bahan bakar batu bara menunjukkan adanya peningkatan konsentrasi emisi gas polutan terhadap udara ambien. Peningkatan $\mathrm{NO}_{\mathrm{x}}$ dipengaruhi oleh sumber bergerak dari aktivitas di sekitar

Air Pollution Simulation From Cirebon Power Plant Activity

(Muhaimin, Eko Sugiharto, Adhitasari Suratman) 
pembangkit listrik yaitu sebesar 90\%. Emisi ini dapat berdampak langsung terhadap kesehatan masyarakat atau lingkungan sekitarnya, sehingga kontrol untuk emisi gas $\mathrm{SO}_{\mathrm{x}}$ dan $\mathrm{NO}_{\mathrm{x}}$ dari pembangkit listrik sangat diperlukan guna mengurangi dampak lingkungan yang merugikan kesehatan masyarakat (Pierla et al., 2008; Ma, 2010; Ali et al., 2010).

Pengaruh keadaan meteorologi seperti temperatur udara dan kecepatan angin dapat berdampak pada dispersi gasgas polutan yang dapat dijelaskan dan dihitung dengan persamaan model gaussian plume. Dispersi polutan sebanding dengan temperatur udara dan berbanding terbalik dengan kecepatan angin (Fatehifar., 2008; Sabri., 2011). Perbedaan musim mempengaruhi konsentrasi polutan $\mathrm{SO}_{2}$ dari pembangkit listrik nantinya berpengaruh terhadap kualitas udara ambien (Palau et al., 2009).

Adapun tujuan dari penelitian ini adalah:

1. Mengetahui konsentrasi polutan di udara ambien akibat dari aktivitas PLTU.

2. Pemodelan dispersi polutan di udara yang berasal dari dua cerobong asap.

\section{Metode Penelitian/Penulisan}

Metode penelitian yang dilakukan untuk mengetahui dispersi polutan di udara dilakukan dengan menggunakan model gaussian plume. Hasil perhitungan ini adalah berupa nilai konsentrasi polutan dan gambar dua dimensi yang menunjukkan dispersi dari polutan. Konsentrasi polutan merupakan fungsi dari jarak terdispersinya polutan. Adapun data yang digunakan dalam penelitian ini merupakan data sekunder yang diperoleh dari PLTU Cirebon.

Pemodelan dispersi polusi udara dalam penelitian ini dilakukan berdasarkan kasus terburuk (worst case) dimana nilai dari semua stabilitas atmosfer (Tabel 1 dan 2) dihitung dan kemudian dicari nilai yang paling tinggi, dan nilai yang paling tinggi tersebut menunjukkan stabilitas dari keadaan atmosfer selama dispersi polutan terjadi. Data yang diperoleh selama satu tahun dari bulan Oktober 2012 sampai dengan September 2013. Data yang digunakan berupa data rata-rata dalam satu tahun tersebut.

\section{Model gaussian plume}

Aspek kualitatif dari teori dispersi polutan di udara adalah untuk mendiskripsikan keadaan emisi di udara dari sumber pencemar (point source). Salah satu model dispersi polutan di udara adalah Model gaussian plume (Coll, 2002). Model gaussian plume sering digunakan untuk memprediksikan dispersi polutan secara kontinyu yang

Air Pollution Simulation From Cirebon Power Plant Activity

(Muhaimin, Eko Sugiharto, Adhitasari Suratman) 
berasal dari permukaan atau dataran tinggi. Hal ini mengasumsikan bahwa dispersi polutan mempunyai distribusi gaussian atau memiliki distribusi probabilitas normal. Model ini mengasumsikan bahwa atmosfer memiliki keadaan yang stagnan, homogen dan konsentrasi dari polutan akan terdistribusi secara normal (Ukaigwe et al, 2013).

Model gaussian plume adalah sebuah pendekatan yang digunakan untuk mempelajari polutan di udara karena adanya turbulen difusi dan adveksi yang disebabkan oleh angin (Stockie, 2011). Adapun persamaan dari Model gaussian plume untuk dispersi polutan di udara ditunjukkan pada persamaan 1 (Weiner dan Matthews, 2003).

$C_{(x y z z)}=\frac{Q}{2 \pi u \sigma_{y} \sigma_{z}} \exp \left(\frac{-y^{2}}{2 \sigma_{y}^{2}}\right)\left(\exp \left(\frac{-(z+H)^{2}}{2 \sigma_{z}^{2}}\right)+\exp \left(\frac{-(z-H)^{2}}{2 \sigma_{z}^{2}}\right)\right)$

di mana:

$\mathrm{C}(\mathrm{x}, \mathrm{y}, \mathrm{z})$ : Konsentrasi polutan $\left(\mathrm{g} / \mathrm{m}^{3}\right)$

$\mathrm{x}$ : Jarak jatuhnya polutan (m)

y : Jarak horizontal dari sumbu sebaran

(m) $\mathrm{z}$ : Jarak vertikal (ketinggian) (m)

$\mathrm{Q}$ : Laju emisi sumber $(\mathrm{g} / \mathrm{s})$

$\mathrm{u}:$ Kecepatan angin $(\mathrm{m} / \mathrm{s})$

$\mathrm{H}$ : Tinggi efektif cerobong (m)

$\sigma_{\mathrm{y}}: 456,11628(\mathrm{x}) \tan \theta:$ Koefisien dispersi searah sumbu y (koefisien lateral (m))

$\theta: 0,017453293[\mathrm{c}-\mathrm{d} \ln (\mathrm{x})]$

$\sigma_{\mathrm{z}}: \mathrm{ax}^{\mathrm{b}}:$ Koefisien dispersi searah sumbu $\mathrm{x}$ (koefisien vertikal (m)).

Koefisien dispersi tersebut tidak saja merupakan fungsi dari jarak tetapi juga bergantung pada kestabilan atmosfir (Nauli, 2002). Koefisien a, b, c dan d disajikan dalam Tabel 1 dan 2 (Vallero, 2008).

Tabel 1. Nilai c dan d untuk $\sigma_{\mathrm{y}}$

\begin{tabular}{lrr}
\hline Stabilitas & $\mathrm{c}$ & $\mathrm{d}$ \\
\hline A & 24,1670 & 2,5334 \\
B & 18,3330 & 1,8096 \\
C & 12,5000 & 1,0857 \\
D & 8,3330 & 0,72382 \\
E & 6,2500 & 0,54287 \\
F & 4,1667 & 0,36191
\end{tabular}

Tabel 2. Nilai a dan b untuk $\sigma_{z}$

\begin{tabular}{|c|r|c|c|}
\hline Stabilitas & \multicolumn{1}{|c|}{ Jarak } & a & b \\
\hline \multirow{4}{*}{ A } & $>3,11$ & & \\
\cline { 2 - 4 } & $0,5-3,11$ & 453,85 & 2,1166 \\
\cline { 2 - 4 } & $0,4-0,5$ & 346,75 & 1,7283 \\
\cline { 2 - 4 } & $0,3-0,4$ & 258,89 & 1,4094 \\
\cline { 2 - 4 } & $0,25-0,3$ & 217,41 & 1,2644 \\
\cline { 2 - 4 } & $0,2-0,25$ & 179,52 & 1,1262 \\
\cline { 2 - 4 } & $0,15-0,2$ & 170,22 & 1,0932 \\
\hline
\end{tabular}

\begin{tabular}{|c|r|c|c|}
\hline Stabilitas & \multicolumn{1}{|c|}{ Jarak } & a & b \\
\hline \multirow{4}{*}{ E } & $>40$ & 47,618 & 0,29592 \\
\cline { 2 - 4 } & $20-40$ & 35,420 & 0,37615 \\
\cline { 2 - 4 } & $10-20$ & 26,970 & 0,46713 \\
\cline { 2 - 4 } & $4-10$ & 24,703 & 0,50527 \\
\cline { 2 - 4 } & $2-4$ & 22,534 & 0,57154 \\
\cline { 2 - 4 } & $1-2$ & 21,628 & 0,63077 \\
\cline { 2 - 4 } & $0,3-1$ & 21,628 & 0,7566 \\
\hline
\end{tabular}

Air Pollution Simulation From Cirebon Power Plant Activity (Muhaimin, Eko Sugiharto, Adhitasari Suratman) 


\begin{tabular}{|c|r|r|r|}
\hline \multirow{4}{*}{} & Jarak & $\mathrm{a}$ & $\mathrm{b}$ \\
\cline { 2 - 4 } & $0,1-0,15$ & 158,08 & 1,0542 \\
\cline { 2 - 4 } & $<0,1$ & 122,8 & 0,9447 \\
\hline \multirow{3}{*}{ B } & $0,4-35$ & 109,300 & 10.971 \\
\cline { 2 - 4 } & $0,2-0,4$ & 98,483 & 0,98332 \\
\cline { 2 - 4 } & $<0,2$ & 90,673 & 0,93198 \\
\hline C & all x & 61.141 & 0,91465 \\
\hline \multirow{4}{*}{ D } & $>30$ & 44,053 & 0,51179 \\
\cline { 2 - 4 } & $10-30$ & 36,650 & 0,56589 \\
\cline { 2 - 4 } & $3-10$ & 33,504 & 0,60486 \\
\cline { 2 - 4 } & $1-3$ & 32,093 & 0,64403 \\
\cline { 2 - 4 } & $0,3-1$ & 32,093 & 0,81066 \\
\cline { 2 - 4 } & 0,3 & 34,459 & 0,86974 \\
\hline
\end{tabular}

\section{Kelas stabilitas atmosfer}

Kondisi stabilitas di atmosfer terkait dengan kemampuan atmosfer untuk mencampur dan menyebar polutan. Kondisi ini juga menentukan kondisi turbulensi di atmosfer dan pembentukan awan. Sebuah metodologi yang diterima secara luas untuk perhitungan stabilitas atmosfer telah diperkenalkan oleh

\begin{tabular}{|c|r|r|r|}
\hline \multirow{4}{*}{} & Jarak & $\mathrm{a}$ & $\mathrm{b}$ \\
\cline { 2 - 4 } & $0,1-0,3$ & 23,331 & 0,81956 \\
\hline & $<0,1$ & 24,260 & 0,8366 \\
\hline \multirow{4}{*}{$\mathrm{F}$} & $>60$ & 34,219 & 0,21716 \\
\cline { 2 - 4 } & $30-60$ & 27,074 & 0,27436 \\
\cline { 2 - 4 } & $15-30$ & 22,651 & 0,32681 \\
\cline { 2 - 4 } & $7-15$ & 17,836 & 0,415 \\
\cline { 2 - 4 } & $3-7$ & 16,187 & 0,4649 \\
\cline { 2 - 4 } & $2-3$ & 14,823 & 0,54503 \\
\cline { 2 - 4 } & $1-2$ & 13,953 & 0,63227 \\
\cline { 2 - 4 } & $0,7-1,0$ & 13,953 & 0,68465 \\
\cline { 2 - 4 } & $0,2-0,7$ & 14,457 & 0,78407 \\
\cline { 2 - 4 } & $<0,2$ & 15,209 & 0,81558 \\
\hline
\end{tabular}

Pasquill. Metodologi ini didasarkan pada pengukuran kecepatan angin pada ketinggian $10 \mathrm{~m}$ dan intensitas radiasi matahari siang hari dan tutupan awan pada malam hari (Lazaridis, 2010). Tabel 3 menunjukkan kelas stabilitas atmosfer berdasarkan pada Pasquill (Beychok, 1994).

Tabel 3. Klasifikasi kelas stabilitas atmosfer

\begin{tabular}{|c|c|c|c|c|c|}
\hline \multirow{3}{*}{$\begin{array}{c}\text { Kecepatan } \\
\text { Angin } \\
(\mathrm{m} / \mathrm{s})\end{array}$} & \multicolumn{3}{|c|}{ Siang } & \multicolumn{2}{|c|}{ Malam } \\
\hline & \multicolumn{3}{|c|}{ Pancaran Sinar Matahari } & \multicolumn{2}{|c|}{ Tertutup Awan } \\
\hline & Kuat & Sedang & Lemah & $\begin{array}{c}\text { Berawan } \\
(>4 / 8)\end{array}$ & $\begin{array}{l}\text { Cerah } \\
(<3 / 8)\end{array}$ \\
\hline$<2$ & A & A-B & B & - & - \\
\hline $2-3$ & A-B & B & $\mathrm{C}$ & $\mathrm{E}$ & $\mathrm{F}$ \\
\hline $3-5$ & $\mathrm{~B}$ & $\mathrm{~B}-\mathrm{C}$ & $\mathrm{C}$ & $\mathrm{D}$ & $\mathrm{E}$ \\
\hline $5-6$ & $\mathrm{C}$ & C-D & $\mathrm{D}$ & $\mathrm{D}$ & $\mathrm{D}$ \\
\hline$>6$ & $\mathrm{C}$ & $\mathrm{D}$ & $\mathrm{D}$ & $\mathrm{D}$ & $\mathrm{D}$ \\
\hline Keterangan & $\begin{array}{l}\mathrm{A}= \\
\mathrm{B}= \\
\mathrm{C}=\end{array}$ & $\begin{array}{l}\text { angat Tic } \\
\text { dak Stak } \\
\text { dikit Ti }\end{array}$ & $\begin{array}{l}\text { k Stabil } \\
\text { k Stabil }\end{array}$ & $\begin{array}{l}\mathrm{D}=\mathrm{N} \\
\mathrm{E}=\mathrm{A} \\
\mathrm{F}=\mathrm{St}\end{array}$ & $\begin{array}{l}\text { ral } \\
\text { k sedik } \\
\text { il }\end{array}$ \\
\hline
\end{tabular}

Air Pollution Simulation From Cirebon Power Plant Activity

(Muhaimin, Eko Sugiharto, Adhitasari Suratman) 


\section{Pembahasan}

\subsection{Persebaran polutan di udara ambien}

Berdasarkan data meteorologi pada bulan Oktober 2012 sampai dengan September 2013 arah angin ditunjukkan pada Gambar 1. Gambar 1 menunjukan bahwa arah angin terlihat dari barat daya ke arah timur laut dengan kecepatan angin rata-rata sebesar $1,91 \mathrm{~m} / \mathrm{s}$.

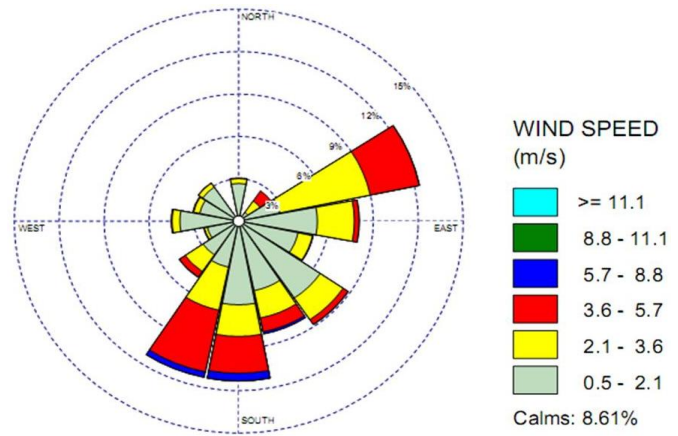

Gambar 1. Arah angin pada bulan Oktober 2012 sampai dengan September 2013

\subsection{Pemodelan dispersi polutan di udara}

Salah satu dampak yang diakibatkan oleh aktivitas PLTU adalah emisi gas buang dari pembakaran batu bara dan debu terhadap kualitas udara ambien. Polutan yang diemisikan dari cerobong asap PLTU adalah berupa $\mathrm{SO}_{\mathrm{x}}$, dan $\mathrm{NO}_{\mathrm{x}} . \quad$ Gas $\mathrm{SO}_{\mathrm{x}}$ dihasilkan dari kandungan sulfur yang ada dalam batu bara, sedangkan gas $\mathrm{NO}_{\mathrm{x}}$ merupakan hasil dari proses pembakaran batu bara. oksigen yang disuplai dari udara bebas yang banyak mengandung nitrogen.

Polutan yang diemisikan dari cerobong asap PLTU tersebut akan terdispersi ke udara ambien, sehingga kualitas udara ambien akan menurun dan akan berdampak pula pada penerima (reseptor) seperti manusia, hewan serta tumbuh-tumbuhan. Untuk mengetahui pola dispersi emisi yang keluar dari cerobong asap PLTU dan konsentrasi polutan di udara, pemodelan dispersi polusi udara dilakukan dengan menggunakan model gaussian plume.

Model gaussian plume sering digunakan untuk memprediksikan dispersi polutan secara kontinyu yang berasal dari permukaan atau dataran tinggi. Hal ini mengasumsikan bahwa dispersi polutan mempunyai distribusi gaussian atau memiliki distribusi probabilitas normal. Model ini mengasumsikan bahwa atmosfer memiliki keadaan yang stagnan, homogen dan konsentrasi dari polutan akan terdistribusi secara normal. Input untuk model ini sangat sederhana yang meliputi kecepatan angin, arah angin, jarak polutan dari sumber dan koefisien dispersi $\sigma_{\mathrm{y}}$ dan $\sigma_{\mathrm{z}}$ (Ukaigwe et al., 2013).

Proses pembakaran ini memerlukan

Air Pollution Simulation From Cirebon Power Plant Activity

(Muhaimin, Eko Sugiharto, Adhitasari Suratman) 
Tabel 4. Konsentrasi Polutan dari hasil Pemodelan

\begin{tabular}{ccc}
\hline Jenis & Konsentrasi & Baku Mutu \\
Polutan & & $\begin{array}{c}\text { Berdasarkan PP No.41 } \\
\text { Tahun 1999 }\end{array}$ \\
& & $60 \mu \mathrm{g} / \mathrm{m}^{3}$ \\
$\mathrm{SO}_{\mathrm{x}}$ & $36,89 \mu \mathrm{g} / \mathrm{m}^{3}$ & $100 \mu \mathrm{g} / \mathrm{m}^{3}$ \\
$\mathrm{NO}_{\mathrm{x}}$ & $31,25 \mu \mathrm{g} / \mathrm{m}^{3}$ & \\
\hline
\end{tabular}

Hasil pemodelan menunjukkan konsentrasi polutan di udara baik $\mathrm{SO}_{\mathrm{x}}$ maupun $\mathrm{NO}_{\mathrm{x}}$ masih berada di bawah baku mutu berdasarkan peraturan pemerintah no. 41 tahun 1999 tentang pengendalian pencemaran udara. Adapun hasil pemodelan dispersi polutan di udara ditunjukkan Tabel 4.

Hasil pemodelan dispersi polusi udara untuk $\mathrm{SO}_{\mathrm{x}}$ dan $\mathrm{NO}_{\mathrm{x}}$ masih berada di bawah baku mutu, hal ini dipengaruhi oleh beberapa faktor diantaranya faktor kecepatan angin dan air hujan. Dengan adanya air hujan, polutan di atmosfer akan mengalami deposisi yang berakibat pada penurunan konsentrasi pada polutan (Verkatram, 2004). Kemudian Semakin besar kecepatan angin maka konsentrasi polutan akan semakin kecil, hal ini

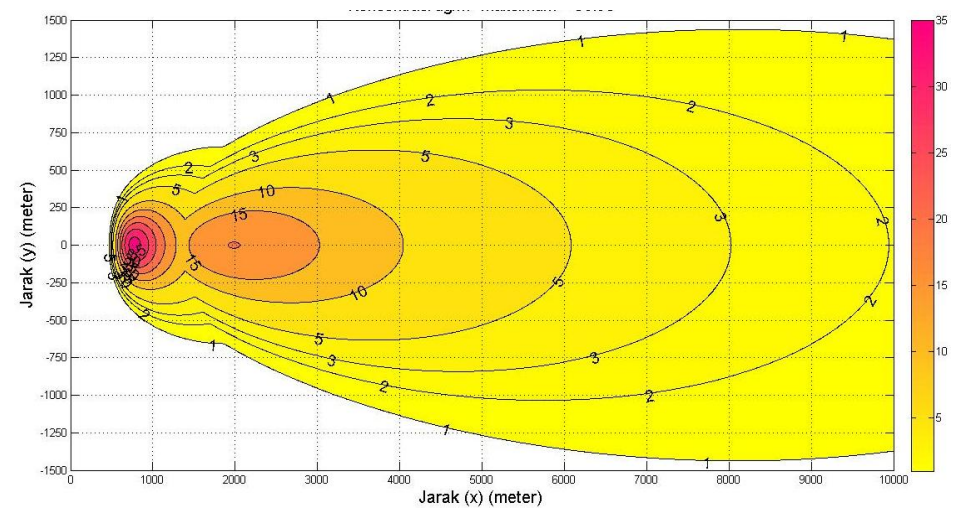

Gambar 2. Pola dispersi polutan $\mathrm{SO}_{\mathrm{x}}$ di udara disebabkan karena dengan kecepatan angin yang besar polutan akan semakin cepat terdispersi oleh udara dan mengakibatkan konsentrasi polutan menjadi menurun dari sumber ke jarak yang lebih jauh dari sumber.

Pola dispersi polutan di udara untuk $\mathrm{SO}_{\mathrm{x}}$ ditunjukkan pada Gambar 2 sedangkan untuk polutan $\mathrm{NO}_{\mathrm{x}}$ ditunjukkan pada Gambar 3. Perbedaan warna pada setiap jarak tertentu menunjukkan tingkat perbedaan konsentrasi, warna magenta menunjukkan kepekatan konsentrasi polutan yang paling tinggi, kemudian untuk warna kuning menunjukkan konsentrasi polutan yang paling tendah. Apabila dilihat pada color bar yang berada pada sebelah kanan gambar, menunjukkan semakin ke bawah maka nilainya akan semakin menurun seiring dengan berubahnya warna dari magenta ke warna kuning. 


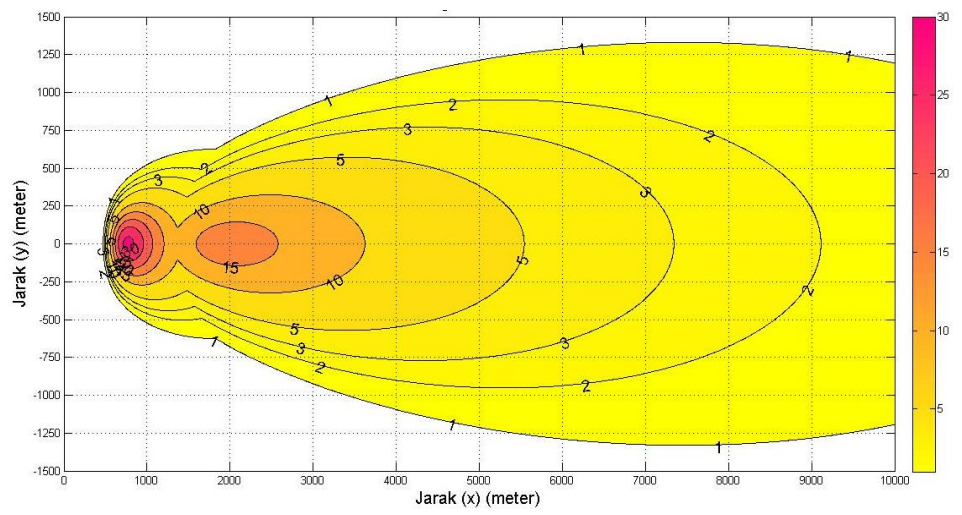

Gambar 3. Pola dispersi polutan $\mathrm{NO}_{\mathrm{x}}$ di udara

\subsection{Pemodelan dispersi polutan di udara dengan menggunakan dua cerobong asap}

Pemodelan dispersi polutan di udara dengan menggunakan dua cerobong asap dilakukan guna mengetahui pola dispersi dan konsentrasi polutan di udara yang berasal dari dua unit PLTU. Spesifikasi dari masingmasing cerobong yang berasal dari PLTU 1 dan PLTU 2 dibuat sama baik secara fisik maupun kondisi polutan yang dikeluarkan, kecuali untuk laju emisi masing-masing polutan.

Laju emisi $\mathrm{SO}_{\mathrm{x}}$ yang digunakan untuk pemodelan dengan menggunakan dua cerobong asap adalah sebesar 18,698 $\mathrm{g} / \mathrm{s}$ sedangkan laju emisi untuk $\mathrm{NO}_{\mathrm{x}}$ yang digunakan adalah 15,841 g/s. Laju emisi yang digunakan ini berdasarkan pada data sekunder yang diperoleh dari PLTU 1. PLTU 1 merupakan PLTU Cirebon Unit 1 yang sudah beroperasi dengan kapasitas 660 MW, sedangkan PLTU 2 merupakan
PLTU Cirebon Unit 2 yang akan dibangun dengan kapasitas 1.000 MW.

PLTU Cirebon Unit 1 dan 2 masing-masing memiliki 1 cerobong asap. Pembangunan PLTU Cirebon Unit 2 akan dilakukan di area yang sama dengan PLTU Cirebon Unit 1, di Desa Kanci, Kabupaten Cirebon, Jawa Barat, atau sekitar 10 kilometer sebelah timur Kota Cirebon. PLTU baru tersebut akan menjadi satu unit sendiri (Sandi, 2013). Pemodelan dilakukan untuk mengetahui konsentrasi maksimum dan dispersi polutan yang berasal dari dua unit PLTU tersebut.

Jarak maksimum jangkauan polutan yang digunakan adalah $10 \mathrm{~km}$ (searah sumbu x), sedangkan jarak untuk arah sebaran polutan menyamping sekitar 1,5 km ke kanan dan kiri dari posisi cerobong asap. Kemudian jarak antar cerobong dibuat 500 meter. Dispersi polutan dalam pemodelan ini dilihat apabila cerobong asap berada pada posisi saling membelakangi (depan-belakang).

Air Pollution Simulation From Cirebon Power Plant Activity

(Muhaimin, Eko Sugiharto, Adhitasari Suratman) 
Adapun hasil pemodelan polusi udara ditunjukkan pada Gambar 4 untuk yang berasal dari dua cerobong asap polutan $\mathrm{SO}_{\mathrm{x}}$ dan Gambar 5 untuk $\mathrm{NO}_{\mathrm{x}}$.

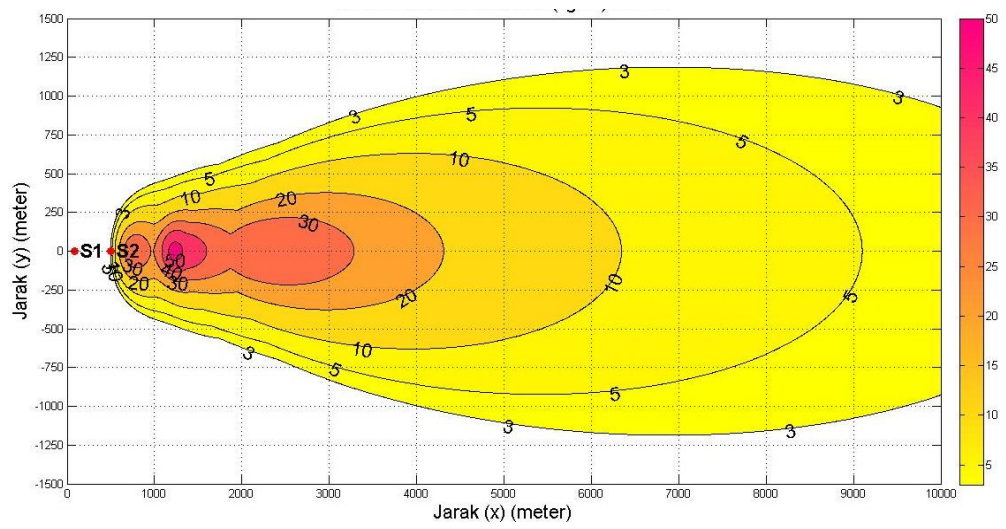

Gambar 4. Pola dispersi polutan $\mathrm{SO}_{\mathrm{x}}$ di udara yang berasal dari dua cerobong asap

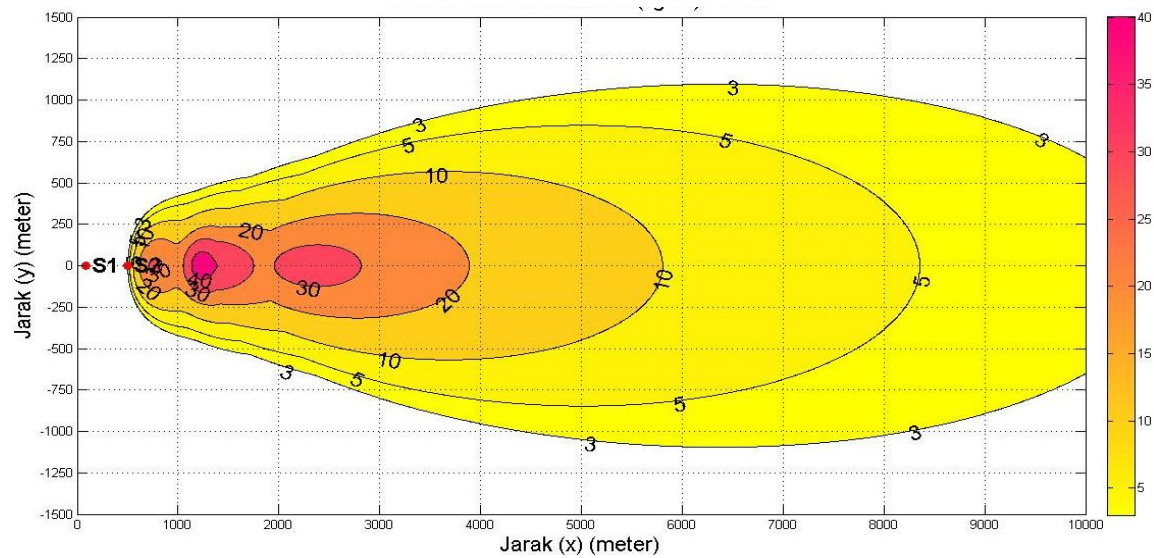

Gambar 5. Pola dispersi polutan $\mathrm{NO}_{\mathrm{x}}$ di udara yang berasal dari dua cerobong asap

Hasil pemodelan menunjukkan bahwa konsentrasi polutan masih berada di bawah baku mutu udara ambien, hal ini disebabkan konsentrasi dari masingmasing polutan sebelum diolah masih berada di bawah baku mutu.

\section{Kesimpulan}

Berdasarkan hasil pemodelan dispersi polusi udara menunjukkan bahwa konsentarsi polutan di udara masih berada di bawah baku mutu berdasarkan pada peraturan pemerintah nomor 41 tahun 1999. Kemudian pemodelan dispersi polutan dengan menggunakan dua cerobong asap menunjukkan konsentrasi polutan yang dihasilkan juga masih berada dibawah baku mutu.

\section{Ucapan Terima kasih}

Ucapan terima kasih penulis sampaikan kepada PLTU Cirebon dan PSLH UGM atas bantuan dan data sekunder yang telah diberikan selama penulis melakukan penelitian.

Air Pollution Simulation From Cirebon Power Plant Activity

(Muhaimin, Eko Sugiharto, Adhitasari Suratman) 


\section{Pustaka}

Ali, M., and Athar M., 2010, Dispersion modeling of noxious pollutants from Thermal power plants, Turkish J.Eng.Env.Sci., 34, $105-120$.

Beychok, M.R.,1994, Fundamental of Stack Gas Dispersion, Newport Beach, California.

Bijaksana, A.M.A., Sjahrul, M., Nadjamuddin Harun, dan Rudy Djamaluddin, 2012, The effects of Gas Emission Steam Power Plant On The Surrounding Residential Area. IJCEE-IJENS. Vol. 12 No: 03.

Coll, J., 2002, Air Pollution. $2^{\text {nd }}$ ed., New Fetter Lane, London.

Fatehifar, E., Elkamel, A.A., Alizadeh O, A. Charchi., 2008, Developing a new model for simulation of pollution dispersion from a network of stacks. Applied Mathematics and Computation 206: 662-668.

Lazaridis, M., 2010, First Principles of Meteorology and Air Pollution. Enviromental Pollution Vol. 19. Springer, London.

Ma, S., 2010, Simulation on $\mathrm{SO}_{2}$ and $\mathrm{NO}_{\mathrm{x}}$ Emission from Coal Fired Power Plants in North-Eastern North America, Energy and Power Engineering,2, 190-195.

Nauli, T., 2002. Pola Sebaran Polutan Dari Cerobong Asap, Prosiding Pertemuan dan Presentasi Ilimiah Penelitian Dasar Ilmu Pengetahuan dan Teknologi Nuklir P3TM-BATAN, Yogyakarta.

Palau, J. L. J., dan Meliá, D. S., 2009, Seasonal Differences In $\mathrm{SO}_{2}$ Ground-Level Impacts From A Power Plant Plume On Complex Terrain, Environ. Monit. Assess., No. 149. p. 445-455.

Pirlea, H. G.A., Brusturean, D. SilaghiPerju, dan D. Perju, 2008, Simulation of $\mathrm{NO}_{2}$ Emission
Dispersion in Timisoara City, in a Certain Reference Point in Relation with A Stationary Source. Chem. Bull. Politehnica Univ. (Timişoara). Volume. 53(67), 1-2.

Sabri, A.A., 2011, Mathematical Model For The Study Effects Of Meteorological Conditions On Dispersion Of Pollutants In Air. Diyala Journal of Engineering Sciences, 04, 02 , 150-165.

Sandi, A. P., 2013, Ekspansi Pltu Cirebon 2 Tunggu Harga Listrik, http://www.tempo.co/read/news/2 013/09/23/090515835/EkspansiPLTU-Cirebon-2-Tunggu-HargaListrik. Diakses tanggal 23 Oktober 2013.

Stockie, John M, 2011, The Mathematics of Atmospheric Dispersion Modeling. SIAM Review. Vol. 53, No. 2, pp. 349-372.

Ukaigwe, Sandra A., dan Osoka, E.C., 2013, Air Quality Monitoring Using Model: A Review. IJSR. Vol.2 ed. 9.

Vallero, Daniel A., 2008, Fundamentals Of Air Pollution, 4th ed., Elsevier, UK.

Venkatram, A., 2004, The Role Of Meteorological Inputs In Estimating Dispersion From Surface Release, Atmos. Environ, 38, 16, 2439-2446.

Wu, Y.L., Rahmaningrum, D.G., Lai, Y.C., Tu, L.K., Lee, S.J., Wang, L.C., and Chien, C.G.P., 2012, Mercury Emissions from a CoalFired Power Plant and Their Impact on the Nearby Environment, Aerosol and Air Quality Research, 12, 643-650.

Weiner dan Matthews, 2003, Environmental Engineering. Fourth Edition. Elsevier Science. USA

Air Pollution Simulation From Cirebon Power Plant Activity

(Muhaimin, Eko Sugiharto, Adhitasari Suratman) 